\title{
Patterns of movement of the limpet Cellana tramoserica on rocky shores and retaining seawalls
}

\author{
F. Bulleri ${ }^{1,2, *}$, M. G. Chapman ${ }^{1}$, A. J. Underwood ${ }^{1}$ \\ ${ }^{1}$ Centre for Research on Ecological Impacts of Coastal Cities, Marine Laboratories A11, University of Sydney, \\ Sydney, New South Wales 2006, Australia \\ ${ }^{2}$ Present address: Scienze Ambientali, Università di Bologna, Via S. Alberto 163, Ravenna 48100, Italy
}

\begin{abstract}
Artificial structures are becoming common features of the landscape in shallow waters of urban areas, but very little is known about their ecology. In Sydney Harbour (NSW, Australia), intertidal seawalls replace considerable portions of natural habitats, including rocky shores. Previous studies have shown that seawalls and rocky shores generally support similar assemblages of plants and animals, with important differences in relative abundances of some species. The behaviour of key consumers can have a fundamental role in structuring benthic assemblages, and it is, therefore, necessary to assess whether it is changed by the replacement of natural habitats with artificial structures. This study compares patterns of movement of the common patellid limpet Cellana tramoserica between seawalls and vertical rocky shores. The distances displaced, the orientation of movement and the homing behaviour of marked individuals were recorded from day to day, over a period of several tidal cycles (14 d) and for a longer period (ca. $3 \mathrm{mo}$ ), on several seawalls and rocky shores. Short-term patterns of movement ( 1 to $14 \mathrm{~d}$ ) did not differ between structures. In contrast, after $3 \mathrm{mo}$, although the orientation of the movement remained random on both kinds of structures, limpets on seawalls had dispersed longer distances and tended not to retain their original positions. These results suggest that long-term dispersal of $C$. tramoserica, rather than foraging bouts, could be altered by the replacement of rocky shores with artificial structures. Differences in use of habitat by key consumers should be incorporated in models aimed at identifying the mechanisms responsible for the occurrence of different assemblages on natural and artificial structures.
\end{abstract}

KEY WORDS: Urbanisation - Seawall · Rocky shore Intertidal $\cdot$ Limpets $\cdot$ Cellana tramoserica Artificial structures $\cdot$ Movement

Resale or republication not permitted without written consent of the publisher

\section{INTRODUCTION}

Following the progressive urbanisation of coastal areas (Yapp 1986, Reilly et al. 1996, Gray 1997), the presence of a variety of artificial structures, such as breakwaters, jetties, groynes, pier pilings, floating pontoons and seawalls is increasing in shallow waters. Despite this tendency, the need to assess changes to natural assemblages of organisms caused by the introduction of artificial structures has only recently been recognised. To date, few studies have investigated patterns of abundance and distribution of organisms associated with artificial structures (but see Connell \&
Glasby 1998, Glasby 1999, Bulleri et al. 2000, Connell 2000, Davis et al. 2002, Bacchiocchi \& Airoldi 2003, Chapman 2003, Chapman \& Bulleri 2003, Bulleri \& Chapman 2004). Fewer studies have focused on factors causing different assemblages of organisms to occur on natural and artificial structures (Glasby 1999, 2000, Holloway \& Connell 2002), and none of these has analysed the behavioural responses of mobile organisms to the replacement of natural habitats by artificial structures. In contrast, some aspects of the behaviour of terrestrial animals, including patterns of predation, mating and foraging, have been thoroughly investigated in human-dominated areas (Robertson et al. 
2000, Bezzel 2001, Faivre et al. 2001, Owings et al. 2001, Markus 2002, Castillo et al. 2003, Sitati et al. 2003, Warne \& Jones 2003).

The behaviour of key consumers can have a major influence on the structure of assemblages. For example, grazers can affect the abundance and distribution of intertidal organisms on rocky shores, directly or indirectly (Underwood 1980, Lubchenco \& Gaines 1981, Hawkins \& Hartnoll 1983, Sousa 1985, Menge 1995, Benedetti-Cecchi 2000, Benedetti-Cecchi et al. 2001). There is much evidence that the behaviour of intertidal animals is not fixed and invariant, but can change through time and space, in relation to physical and biological cues (Hazlett 1988, Little 1989, Chapman \& Underwood 1992, Crowe 1999, Foster \& Endler 1999, Williams et al. 1999, Chapman 2000a). For instance, patterns of movement of some intertidal gastropods are influenced by many environmental factors, including cover of standing water and algae, topographic complexity and presence of sessile invertebrates (Hawkins \& Hartnoll 1983, Minchinton \& Ross 1999, Ruiz Sebastián et al. 2002). Similarly, patterns of aggregation and movement of predatory whelks can be affected by the time of emersion and availability of shelter and prey (Moran 1985, Fairweather 1988). Changes to the structure of natural habitats, for example, through the introduction of built structures, the physical and chemical attributes of which differ from those of the natural habitats they have replaced, could have repercussions for the patterns of movement and dispersion of herbivores (see also Fahrig 2001).

The patellid limpet, Cellana tramoserica (Sowerby), is a common intertidal grazer on rocky shores of southeastern Australia. These limpets feed mainly on microalgae and play an important role in determining the structure of mid-shore assemblages (Underwood \& Jernakoff 1981, Underwood et al. 1983, Underwood 1984).

Studies on exposed rocky shores have shown that random movement and homing behaviour are not discrete patterns in populations of Cellana tramoserica (Mackay \& Underwood 1977). Limpets are regularly dispersed on low- and mid-shore areas of rock platforms, and these patterns are probably caused and maintained by homing to particular sites, unless disturbed by the proximity of conspecifics (Mackay \& Underwood 1977). The response of a limpet to the presence of another individual is then to move away in a random direction. Moreover, Underwood et al. (1983) showed that $C$. tramoserica migrate away from areas with large densities of barnacles and, when forced to stay in such areas, eventually lose weight and starve, suggesting that movement and foraging of these animals may be reduced on topographically complex surfaces.
In Sydney Harbour (NSW, Australia), Cellana tramoserica are commonly found on seawalls and rocky shores (Chapman \& Bulleri 2003). Although most of the rocky shores in the area are horizontal, with relatively small vertical surfaces (Chapman \& Bulleri 2003), there are reasons to expect the movement and homing of $C$. tramoserica to differ between natural and artificial structures even when surfaces with the same slope (vertical) are compared. First, the vertical extent of seawalls, which encompasses the entire intertidal range, is generally greater than that of the rocky shores, where vertical ledges are primarily low on the shore and are often topped by horizontal platforms. Second, high- and mid-shore assemblages of sessile organisms on seawalls are different from those on rocky shores (Chapman \& Bulleri 2003, F. Bulleri, M. G. Chapman \& A. J. Underwood unpubl. data), potentially affecting patterns of movement of gastropods (Hawkins \& Hartnoll 1983, Underwood et al. 1983, O'Donnell 1984). Finally, there are gross differences in topographic complexity between these structures, e.g. crevices among blocks on seawalls, which could alter patterns of movement of grazers (Levings \& Garrity 1983, Fairweather 1988, Underwood \& Chapman 1989, Chapman 2000a). Therefore, it is proposed that intrinsic differences between rocky shores and seawalls affect patterns of movement of C. tramoserica. In particular, this study tests the hypotheses that the distance displaced, the orientation of movement and the number of animals displaying homing behaviour, over different periods of time, differ between rocky shores and seawalls. Movements from day to day, over a period of several tidal cycles (14 d) and for a longer period (ca. $3 \mathrm{mo}$ ) were examined in 2 different experiments, to test for generality of patterns of movement through time.

\section{MATERIALS AND METHODS}

Study sites. This study was done in Sydney Harbour between February and May 2001; 5 seawalls and 5 rocky shores (hereafter referred to as SW and RS, 1 to 5), were haphazardly chosen at the beginning of the study, from all those available (Fig. 1). On each of these structures, an area from 4 to $6 \mathrm{~m}$ in length was selected at high- to mid-shore levels. The sizes of the areas varied slightly, according to the local density of Cellana tramoserica, because a minimum of 50 individuals was marked in each location for the experiment. In order to compare the movement of limpets between seawalls and rocky shores without any confounding effect of the orientation of the substratum, areas on natural rocky shores were selected on vertical surfaces. Limpets were generally found above sessile invertebrates, such as oysters and tubeworms, from 0.6 to $0.9 \mathrm{~m}$ above 


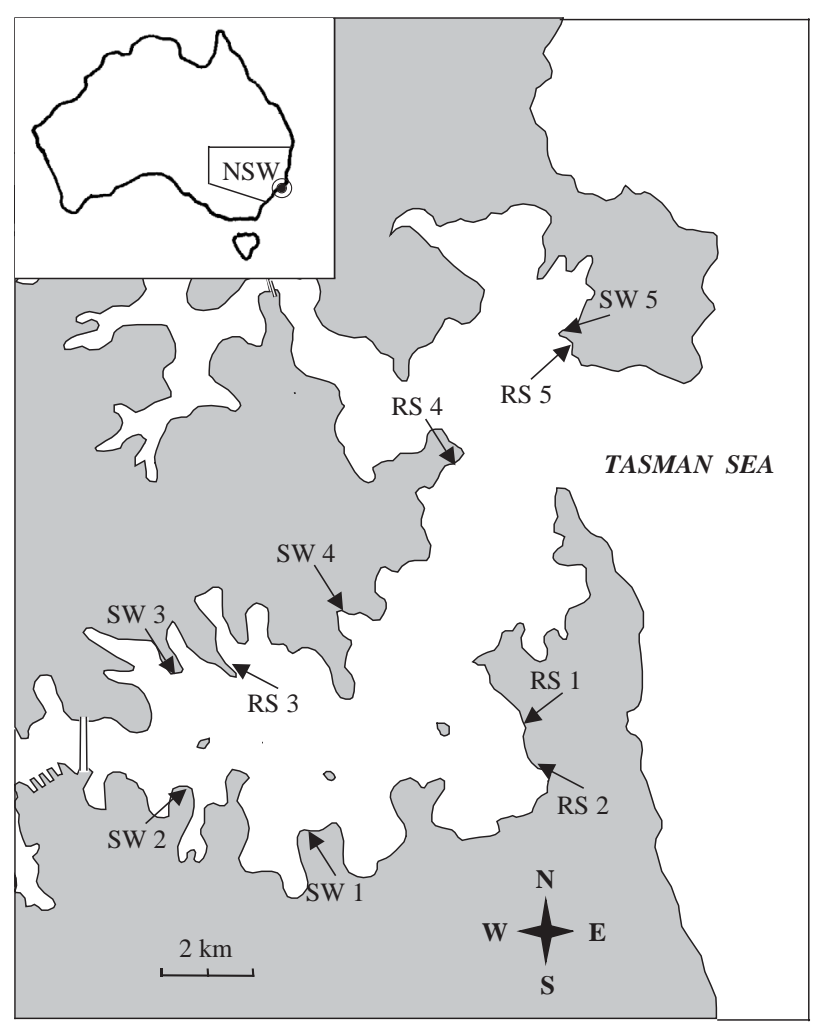

Fig. 1. Map showing the rocky shores (RS) and the seawalls (SW) studied in Sydney Harbour (NSW, Australia)

mean low water (MLW). Higher on the shore, the substratum was primarily bare rock, with sparse patches of encrusting algae, such as Ralfsia verrucosa and Hildenbrandia rubra and barnacles, mainly Tesseropora rosea, Chthamalus antennatus and Chamaesipho tasmanica (Chapman \& Bulleri 2003). All limpets found within the selected areas were, however, included in the study, irrespective of the height on the shore at which they were found.

Experimental design. At each location, at least 50 animals, with a shell length of no less than $2.5 \mathrm{~cm}$, were marked with a plastic numbered label, glued to the shell. Labels were then coated with transparent nail polish to provide further protection. Previous studies have shown little disturbance associated with marking intertidal snails in situ (Chapman 1986). The animals were not dislodged, minimising any disturbance associated with handling. The position on the shore of marked limpets was recorded as the distance from 2 fixed points (Underwood 1977). The distance and direction moved by an individual in a given period of time was calculated by co-ordinate geometry, using paired measures at the beginning and at the end of any chosen period of time (Underwood 1977). Using this method, the displacement of a limpet in the field can be estimated with an error of $\pm 1 \mathrm{~cm}$, and, therefore, individuals that moved $<1 \mathrm{~cm}$ were considered not to have moved, or to have returned to the same position (Mackay \& Underwood 1977). Movement was measured as the orientation and linear distance displaced after periods of $1 \mathrm{~d}$ ( 2 tidal cycles), $14 \mathrm{~d}$ and ca. 3 mo. The measure of displaced distance does not take into account the path followed by an individual, potentially leading to an underestimate of the real distance moved (Underwood 1977, Erlandsson et al. 1999, Chapman 2000b). The experiment was run twice (hereafter referred to as Start 1 and Start 2) for each elapsed time and 25 individuals, out of the 50 marked at the beginning, were assigned at random to each of the 2 experimental starts, providing independent data through time (Underwood 1997). Because it was not feasible to visit all of the 10 study locations on the same day, each of the 2 experimental trials was initiated at only 1 location on a day and, hence, measures either after 1 or $14 \mathrm{~d}$ were not taken simultaneously at the different locations.

Finally, the positions of marked limpets were recorded again after a period of about 3 mo from the start of the first experiment. At each location, the density of Cellana tramoserica $(>2.5 \mathrm{~cm}$ in shell length) was quantified at the beginning of the study, counting the number of individuals within ten $20 \times$ $30 \mathrm{~cm}$ randomly placed quadrats.

Statistical analyses. The density of Cellana tramoserica was compared between rocky shores and seawalls by means of a 2-factor ANOVA model, including Structure (fixed) and Location (random, nested within Structure).

Distances moved by non-homing limpets after $1 \mathrm{~d}$ or 14 d were analysed by 3-factor, nested ANOVAs, including Structure (fixed and orthogonal), Location (random and nested within Structure) and Start [random and nested within Location (Structure)]. Because the data from 1 and $14 \mathrm{~d}$ were analysed separately, the same individuals could be used for the 2 sets of analyses. The ANOVA model used to analyse distances displaced by limpets after 3 mo included the factors Structure (fixed) and Location (random and nested within Structure), but not the factor Start, because of the relatively small number of tagged limpets recovered. Furthermore, after $3 \mathrm{mo}$, no tagged animals were found at 1 of the rocky reefs (RS4, see Fig. 1). Therefore, 1 of the seawalls (SW1) was randomly eliminated from the analysis to keep the design balanced, so that there were 4 locations for each level of the factor Structure. Movements of intertidal gastropods are generally exponentially distributed, so distances were transformed to natural logarithms (Underwood 1977).

The percentage of homing limpets (those defined to be within a radius of $1 \mathrm{~cm}$ from their original position), 


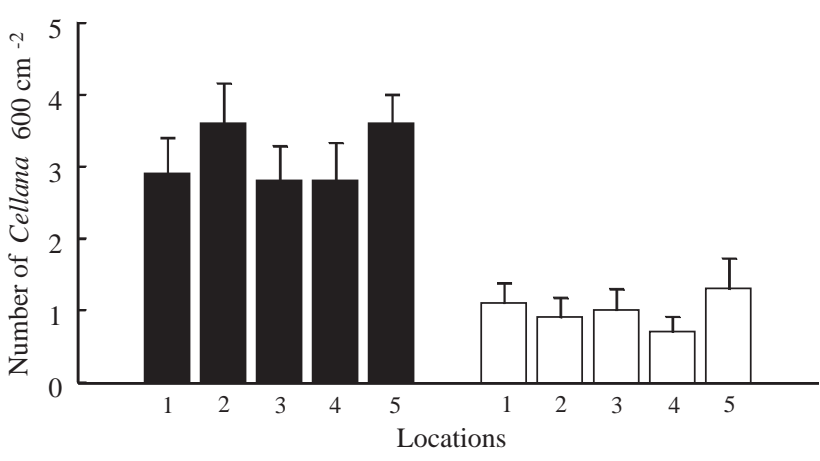

Fig. 2. Cellana tramoserica. Density (+SE) of limpets $>2.5 \mathrm{~cm}$ on rocky shores (filled) and seawalls (unfilled); $\mathrm{n}=10$

after 1 and 14 d was compared between structures by means of 2-factor ANOVAs, including Structure (fixed) and Start of the experiment (random and orthogonal), with Locations as the replicates. Variances of data were not heterogeneous, so data were analysed untransformed.

Rayleigh's test (Mardia 1972) was used to assess whether the movement of limpets was directional or randomly orientated, separately for each location and time.

\section{RESULTS}

The density of Cellana tramoserica (Fig. 2) was significantly greater on rocky shores than on seawalls (analysis of variance of untransformed data; $C=0.18$, $\left.\mathrm{p}>0.05 ; \mathrm{MS}_{\text {Structure }}=114.49, F_{1,8}=100.43, \mathrm{p}<0.001\right)$, and differences were consistent among locations $\left(\mathrm{MS}_{\text {Location (Structure) }}=1.14, F_{8,90}=0.66\right.$, not significant).

The linear distance displaced by Cellana tramoserica over 1 and $14 \mathrm{~d}$ did not differ between rocky shores

Table 1. Cellana tramoserica. Analyses of mean distance displaced by limpets after $1 \mathrm{~d}$ and after $14 \mathrm{~d}$ on different structures at different locations and starts of the experiment. ${ }^{*} \mathrm{p}<0.05 ;{ }^{* *} \mathrm{p}<0.01 ;{ }^{* * *} \mathrm{p}<0.001 ; \mathrm{ns}$ : not significant. $\mathrm{Ln}=$ natural logarithm

\begin{tabular}{|c|c|c|c|c|c|}
\hline \multirow{2}{*}{ Source of variation } & \multirow[t]{2}{*}{$\mathrm{df}$} & \multicolumn{2}{|c|}{$1 \mathrm{~d}$} & \multicolumn{2}{|c|}{$14 \mathrm{~d}$} \\
\hline & & MS & $F$ & MS & $F$ \\
\hline Structure $=\mathrm{S}$ & 1 & 2.53 & 0.49 & 0.23 & 0.03 \\
\hline $\begin{array}{l}\text { Location (Structure) } \\
=\mathrm{L}(\mathrm{S})\end{array}$ & 8 & 5.13 & 1.14 & 6.95 & $6.22^{* *}$ \\
\hline Start $[\mathrm{L}(\mathrm{S})]$ & 10 & 4.51 & $3.42^{* * *}$ & 1.12 & 0.93 \\
\hline Residual & 280 & 1.32 & & 1.20 & \\
\hline Transformation & & Ln & & $\mathrm{Ln}$ & \\
\hline Cochran's test & & $\mathrm{ns}$ & & * & \\
\hline
\end{tabular}

and seawalls (Fig. 3, Table 1). The distance displaced after $1 \mathrm{~d}$ varied significantly from one experimental start to the other, while that after $14 \mathrm{~d}$ varied significantly among locations (Table 1). In contrast, the distance displaced by limpets after about 3 mo (Fig. 4) was significantly greater on seawalls than on rocky shores $\left(C=0.25, \mathrm{p}>0.05 ; \mathrm{MS}_{\text {Structure }}=11.04, F_{1,6}=5.91\right.$, $\mathrm{p}<0.05)$. The distance moved by limpets after this period of time did not vary significantly among locations $\left(\mathrm{MS}_{\text {Location (Structure) }}=1.90, F_{6,72}=2.07, \mathrm{p}>0.05\right)$.

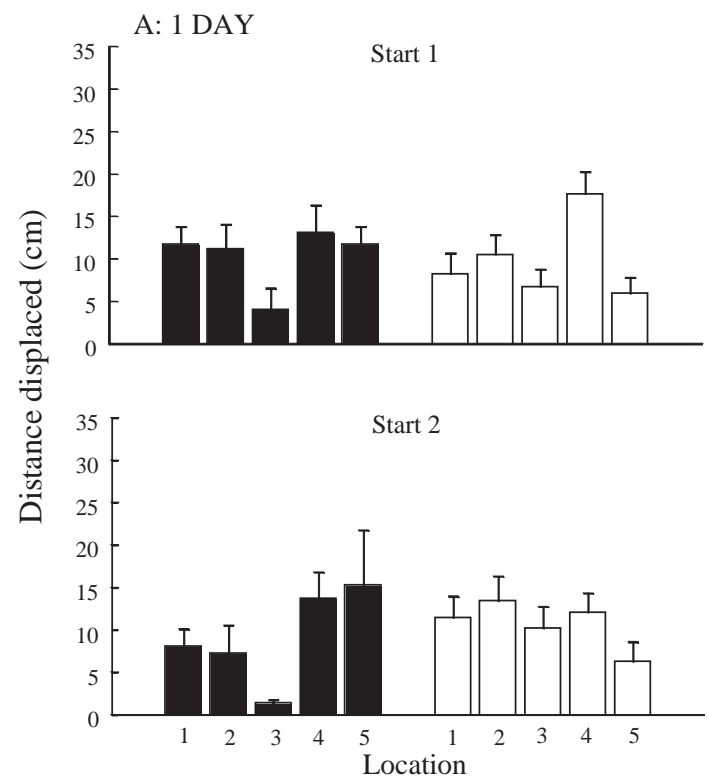

B: 14 DAYS

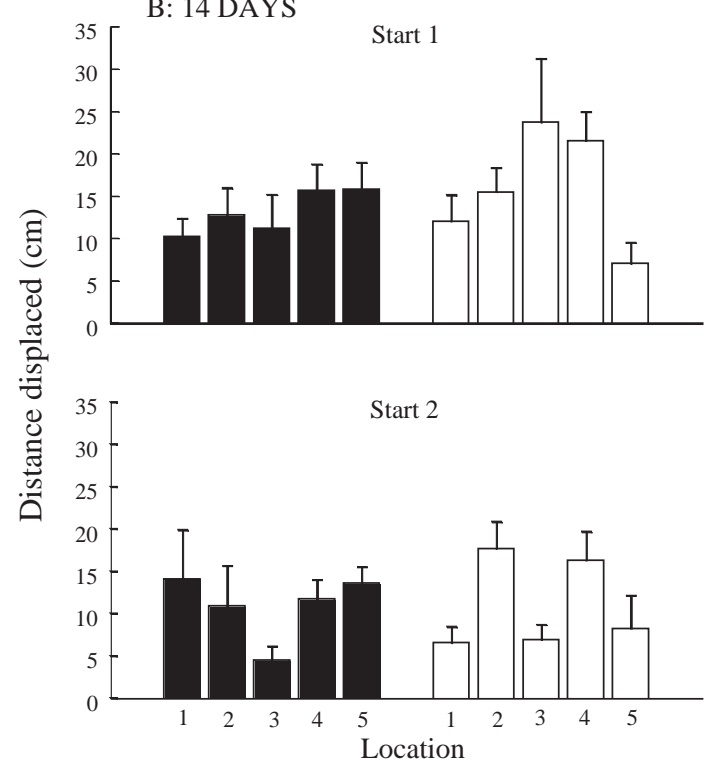

Fig. 3. Cellana tramoserica. Mean distance (+SE) displaced by limpets on rocky shores (filled) and seawalls (unfilled) after (A) $1 \mathrm{~d}$ and (B) $14 \mathrm{~d}$, separately for each combination of location and start of the experiment; $\mathrm{n}=15$ 


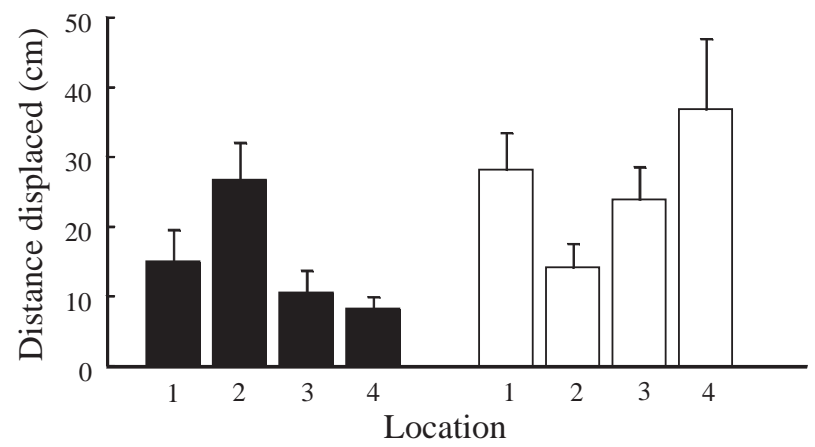

Fig. 4. Cellana tramoserica. Mean distance (+SE) displaced by limpets on rocky shores (filled) and seawalls (unfilled) after about 3 mo, separately for each location; $\mathrm{n}=10$

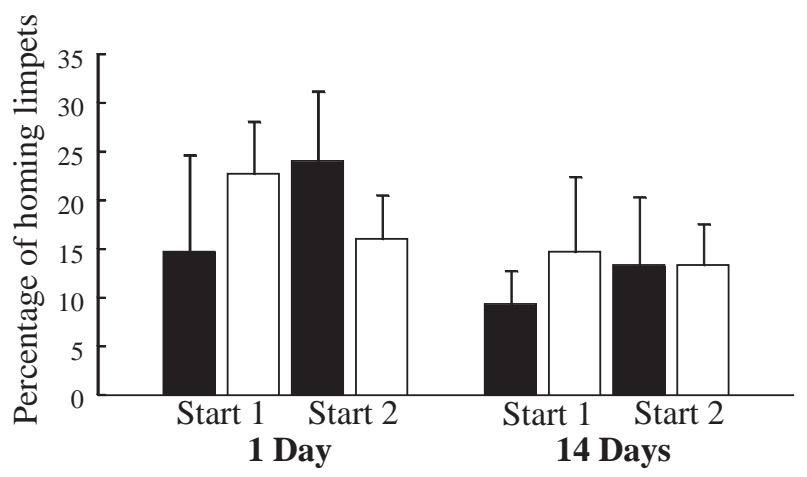

Fig. 5. Cellana tramoserica. Mean percentage (+SE) of homing limpets on rocky shores (filled) and seawalls (unfilled) after $1 \mathrm{~d}$ and $14 \mathrm{~d}$, separately for each start of the experiment; $\mathrm{n}=5$

The proportion of limpets homing after 1 and $14 \mathrm{~d}$ did not differ between rocky shores and seawalls for each start of the experiment (Fig. 5, Table 2). After $3 \mathrm{mo}, 10 \%$ (15 individuals) of the limpets were found in their original positions on rocky shores (averaged across replicates of each type of structure), while none was found in its original position on the seawall. This difference was significant $\left(\chi^{2}, 1 \mathrm{df}=17.6, \mathrm{p}<0.001\right)$.

Because of the limited vertical extension of rocky shores in comparison to seawalls, we expected differences in the orientation of movements of Cellana tramoserica between structures. After $1 \mathrm{~d}$, the movement of limpets was orientated on seawalls and rocky shores (Rayleigh's test; $\mathrm{p}<0.05$ ), for the first and second start of the experiment, respectively. In contrast, after $14 \mathrm{~d}$ and $3 \mathrm{mo}$, the direction of movement of limpets on both seawalls and rocky shores was not distinguishable from random (Rayleigh's test; $\mathrm{p}>0.05$ ). Since, there is no logic in comparing the mean directions when the movement is randomly orientated (Chapman 2000b), hypotheses concerning the orientation of the movement of $C$. tramoserica were not further tested.
Table 2. Cellana tramoserica. Analyses of mean percentage of homing limpets between rocky shores and seawalls and between start times of the experiments (Start), after $1 \mathrm{~d}$ and after $14 \mathrm{~d}$. ns: not significant

\begin{tabular}{|lrrrrr|}
\hline \multirow{2}{*}{ Source of variation } & df & \multicolumn{2}{c}{$1 \mathrm{~d}$} & \multicolumn{2}{c|}{$14 \mathrm{~d}$} \\
& & MS & $F$ & \multicolumn{1}{c|}{ MS } & $F$ \\
\hline Structure & 1 & 0.00 & 0.00 & 35.54 & 1.00 \\
Start & 1 & 8.87 & 0.04 & 8.90 & 0.05 \\
Structure $\times$ Start & 1 & 320.16 & 1.27 & 35.54 & 0.21 \\
Residual & 16 & 251.08 & & 172.19 & \\
Transformation & \multicolumn{3}{c}{ None } & & None \\
Cochran's test & & ns & & ns \\
& & & & & \\
\end{tabular}

\section{DISCUSSION}

Although many studies of movements of large grazing limpets have been done on artificial structures (e.g. Hawkins \& Hartnoll 1983, Gray \& Naylor 1996, Santini et al. 2004), there have been no comparisons with natural rocky habitats. How changes to natural habitats might affect patterns of movement and, hence, the grazing activity of limpets remains, therefore, unexplored.

Distances displaced by Cellana tramoserica and the proportion of homing individuals did not differ between rocky shores and seawalls over relatively short periods of time ( 1 or $14 \mathrm{~d}$ ). After $1 \mathrm{~d}$, the movement of limpets was significantly orientated on seawalls for Start 1 and on rocky shores for Start 2. In general, however, it was not possible to identify clearly the direction in which they were orientated. By contrast, patterns of movement of $C$. tramoserica over a longer period of time (about $3 \mathrm{mo}$ ) differed between structures, in that the distance displaced was larger on seawalls and the number of homing limpets was larger on rocky shores.

Overall, these results show that some aspects of the movement of Cellana tramoserica differ between vertical rocky shores and seawalls, but the nature and magnitude of differences depend on the period of time over which observations are taken. There was no evidence that short-term movements of $C$. tramoserica differed between structures. Rather, the movement of this limpet over 2 tidal cycles varied from random to orientated, irrespective of whether surfaces were natural or artificial. Intertidal gastropods can display temporally variable and unpredictable patterns of movement and activity, responding to sudden changes in environmental conditions, like wave-wash (Wells 1980, Hawkins \& Hartnoll 1983, Little 1989, Crowe 1999, Chapman 2000c) and weather (Hamilton 1977). Short-term patterns of orientation of the movement of C. tramoserica on rocky shores and seawalls in Sydney Harbour are in good agreement with the random-walk model used by 
Underwood (1977) and by Mackay \& Underwood (1977) to describe the movement of non-homing $C$. tramoserica on the coast of NSW (Australia). These authors showed, however, that individuals that were not homing moved at random, consistently over periods of time ranging from 1 to $14 \mathrm{~d}$. Since their studies were done on horizontal rocky platforms at exposed sites, exposure to wave action, the slope of the substratum, or a combination of the two, could have affected the orientation of the movement of $C$. tramoserica (Hawkins \& Hartnoll 1982, Chapman \& Underwood 1992, Williams et al. 1999, Santini et al. 2004).

On the other hand, after $14 \mathrm{~d}$ and after 3 mo, movement was random on rocky shores and on seawalls and was consistent between experimental starts. Therefore, whether short-term movements of Cellana tramoserica on vertical surfaces might vary from random to orientated, possibly in response to external cues, cumulative movement became random over longer periods of time.

Several factors may have influenced distances displaced by Cellana tramoserica on rocky shores and seawalls over 3 mo. Intrinsic differences in the topography of natural and artificial structures could determine the ability of $C$. tramoserica to move on each structure. Underwood \& Chapman $(1985,1989)$ and Chapman (2000a) have shown that linear distances displaced by gastropods are generally greater on flat, simpler surfaces. Although not quantified in the present study, the surface of sandstone blocks, of which seawalls are made, appeared to be smoother than that of rocky shores, potentially enabling limpets to travel longer distances. Nonetheless, tagged limpets on seawalls were observed on the same block for the entire duration of the study, suggesting that the presence of deep crevices between contiguous blocks, due to the erosion of the cementing material (concrete or mortar) by wave action, may have limited the ability of limpets to move across blocks. The greater distances moved by limpets on seawalls would, however, indicate that the blocks were large enough not to constrain their foraging bouts.

Since the availability of bare space decreases from high- to low-shore levels on each structure (Chapman \& Bulleri 2003), attributes of epibenthic assemblages on rocky shores and seawalls could have played an important role lower on the shore, irrespective of any effects of topography. The occurrence of different midshore sessile assemblages between rocky shores and seawalls (Chapman \& Bulleri 2003, F. Bulleri, M. G. Chapman \& A. J. Underwood unpubl. data) may thus have influenced patterns of movement of grazers. Limpets are generally unable to move and forage over irregular surfaces, such as those dominated by barna- cles (Creese 1982, Hawkins \& Hartnoll 1983, Underwood et al. 1983, Dungan 1986). In particular, it has been shown that Cellana tramoserica is not able to move across dense algal beds (Underwood \& Jernakoff 1981) or dense mats of the tubeworm Galeolaria caespitosa (O'Donnell 1984). Because space at mid-shore levels is generally dominated by Hildenbrandia rubra and G. caespitosa, on rocky shores and seawalls, respectively (F. Bulleri, M. G. Chapman \& A. J. Underwood unpubl. data), distances displaced by limpets would be expected to be larger on the former than on the latter type of surface. Ruiz Sebastián et al. (2002) found that the limpet, Scutellastra argenvillei, moved larger distances and homed less within the matrix of the introduced mussel, Mytilus galloprovincialis, than on natural or experimental patches of bare rock. The same authors invoked different mechanisms to explain these patterns, including the difficulty in forming home-scars and the inaccessibility of food within mussel beds. During high or low tide, C. tramoserica were rarely observed resting or crawling within beds of $G$. caespitosa, but were mainly found on bare rock or on patches of substratum covered by encrusting algae (F. Bulleri pers. obs.). Due to the limited availability of suitable substratum, limpets might have been forced to travel longer distances on seawalls to find adequate food supplies. While C. tramoserica on rocky shores could be able to feed within a small and relatively permanent area, individuals on seawalls could need to change their 'feeding grounds' frequently, exploiting resources across the entire block. This model would be further supported by the fact that there were no limpets homing on seawalls after about $3 \mathrm{mo}$, while, on rocky shores, about $10 \%$ of tagged specimens were still found in their original position. Alternatively, differences in the abundance and distribution of microalgae, which represent the main source of food for C. tramoserica (Underwood \& Jernakoff 1981, Underwood et al. 1983, Underwood 1984), between seawalls and rocky shores might explain different long-term patterns of movement.

Some authors (Breen 1971, 1972, Branch 1975) have shown that patterns of movement of limpets can be dependent on densities, of either the same or another species. Mackay \& Underwood (1977) reported that density dispersal occurred rapidly (within a few days) in Cellana tramoserica and that changes in homing behaviour regulated local density (see also Underwood 1988). In particular, they showed that when an introduced limpet came in contact with a limpet sitting in its scar, one of the two moved away at random, emigrating from the crowded area. According to this model, it should be predicted that encounters among limpets would be more frequent on rocky shores (large density) than on seawalls (small density), leading to a 
smaller number of homing limpets on the former type of structure. Surprisingly, in this study the number of homing limpets did not differ between rocky shores and seawalls after 1 and $14 \mathrm{~d}$, while more limpets retained their scars on rocky shores after 3 mo. Densities of $C$. tramoserica on rocky shores were smaller than natural densities recorded by Underwood (1977) and Mackay \& Underwood (1977) on horizontal, exposed rocky platforms and, thus, were possibly not large enough to trigger a dispersal response nor to influence homing. Indeed, Creese \& Underwood (1982) did not record large rates of mortality of $C$. tramoserica in experimental enclosures kept at densities larger than those found here on rocky shores (ca. 7 individuals $600 \mathrm{~cm}^{-2}$ ).

Densities of limpets, within the order of magnitude found in this study, may have affected the distances displaced over longer periods of time. Underwood (1988), however, found that there was no effect of the density on the distance travelled by Cellana tramoserica, although observations were limited to a relatively short period of time ( $3 \mathrm{~d})$. Furthermore, whether longterm patterns of movement of limpets are density dependent, according to patterns of dispersal reported by Aitken (1962) and Breen (1971), larger distances should be expected on rocky shores (large density) than on seawalls (small density), due to individuals emigrating from crowded areas. Since the opposite pattern emerged in this study, it could be argued that physical and biological features (i.e. habitat structure, characteristics of sessile assemblages) of seawalls and rocky shores, rather than differences in densities of limpets, caused variation in the distances displaced (Levings \& Garrity 1983, Iwasaki 1999, Chapman 2000a). Manipulative experiments, involving different densities of C. tramoserica on each type of substratum, represent the only effective tool to determine whether differences in distances travelled by limpets on rocky shores and seawalls are directly induced by differences in biotic or physical attributes between structures, or whether they are an indirect effect of different densities.

Although short-term patterns of movement did not differ between structures, long-term patterns of movement did. This suggests that long-term dispersal of Cellana tramoserica, rather than patterns of movement during individual foraging bouts, may be altered by the replacement of natural shores with artificial structures. Therefore, studies aiming to investigate patterns of movement of intertidal organisms should encompass varying periods of time. Similar recommendations were made by Iwasaki (1999), who found that, over short periods of time ( 4 to $5 \mathrm{~d}$ ), the limpet Patella flexuosa was not able to move across irregular layers of mussels from one bare patch to another, whereas it could over longer periods of time $(1 \mathrm{mo})$. Short-term monitoring may lead to erroneous conclusions about patterns of movement and dispersal of gastropods, in addition to incorrect inference about their effects on other components of intertidal assemblages.

Changes in the behaviour of key invertebrates have the potential to modify the biodiversity and function of intertidal and subtidal ecosystems (Moran 1985, Vadas et al. 1986). The limpet Cellana tramoserica plays an important role in determining the structure of intertidal assemblages, and further study would be needed to establish the impact of changes in its behaviour on the composition and productivity of assemblages (e.g. Underwood \& Jernakoff 1981, Underwood et al. 1983). Different use of habitat may, in fact, contribute to the establishment of different patterns of distribution of animals and plants on natural and artificial structures (Chapman \& Bulleri 2003, F. Bulleri, M. G. Chapman \& A. J. Underwood unpubl. data). Without understanding how grazers use different types of artificial habitats (e.g. seawalls, breakwaters, pier pilings) in comparison to natural habitats, the effects of the introduction of artificial structures cannot be fully appreciated. In order to gain a comprehensive understanding of these effects, future studies should incorporate analyses of the behaviour of important consumers at appropriate spatial and temporal scales.

Acknowledgements. We wish to thank T. P. Crowe, T. J. Willis and 3 anonymous referees for helpful comments on an earlier draft of the manuscript, and C. Olabarría, S. Montéiro and C. Samsa for their help in tagging and tracking limpets. This research was done as part of the requirements for a $\mathrm{PhD}$ submitted by F.B., who was supported by an IPRS/IPA scholarship from the University of Sydney and funds from the Australian Research Council to the Centre for Research on Ecological Impacts of Coastal Cities. The manuscript was partially written while F.B. was supported by a post-doctoral fellowship from the EU (DELOS project) at the Centro Interdipartimentale di Ricerca per le Scienze Ambientali, Università di Bologna.

\section{LITERATURE CITED}

Aitken JJ (1962) Experiments with populations of the limpet Patella vulgata L. Ir Nat J 14:12-15

Bacchiocchi F, Airoldi L (2003) Distribution and dynamics of epibiota on hard structures for coastal protection. Estuar Coast Shelf Sci 56:1157-1166

Benedetti-Cecchi L (2000) Predicting direct and indirect interactions during succession in a mid-littoral rocky shore assemblage. Ecol Monogr 70:45-72

Benedetti-Cecchi L, Bulleri F, Acunto S, Cinelli F (2001) Scales of variation in the effects of limpets on rocky shores in the northwestern Mediterranean. Mar Ecol Prog Ser 209:131-141

Bezzel E (2001) Does only the sparrow survive? Birds in exploited landscapes. J Ornithol 142:160-171

Branch GM (1975) Mechanisms reducing intraspecific com- 
petition in Patella spp.: migration, differentiation and territorial behaviour. J Anim Ecol 44:575-600

Breen PA (1971) Homing behaviour and population regulation in the limpet Acmea (Collisella) digitalis. Veliger 14: 177-183

Breen PA (1972) Seasonal migration and population regulation in the limpet Acmea (Collisella) digitalis. Veliger 15: 133-141

Bulleri F, Chapman MG (2004) Intertidal assemblages on artificial and natural habitats in marinas on the north-west coast of Italy. Mar Biol 145:381-391

Bulleri F, Menconi M, Cinelli F, Benedetti-Cecchi L (2000) Grazing by two species of limpets on artificial reefs in the northwest Mediterranean. J Exp Mar Biol Ecol 255:1-19

Castillo E, Priotti J, Ambrosio AM, Provensal MC, Pini N, Morales MA, Steinmann A, Polop JJ (2003) Commensal and wild rodents in an urban area of Argentina. Int Biodeterior Biodegr 52:135-141

Chapman MG (1986) Assessment of some controls in experimental transplants of intertidal gastropods. J Exp Mar Biol Ecol 103:181-201

Chapman MG (2000a) A comparative study of differences among species and patches of habitat on movements of three species of intertidal gastropods. J Exp Mar Biol Ecol 244:181-201

Chapman MG (2000b) Poor design of behavioural experiments gets poor results: examples from intertidal habitats. J Exp Mar Biol Ecol 250:77-95

Chapman MG (2000c) Variability of foraging in highshore habitats: dealing with unpredictability. Hydrobiologia 426:75-87

Chapman MG (2003) Paucity of mobile species on constructed seawalls: effects of urbanization on biodiversity. Mar Ecol Prog Ser 264:21-29

Chapman MG, Bulleri F (2003) Intertidal seawalls-new features of landscape in intertidal environments. Landsc Urban Plann 62:159-172

Chapman MG, Underwood AJ (1992) Foraging behaviour of marine benthic grazers. In: John DM, Hawkins SJ, Price JH (eds) Plant-Animal interactions in marine benthos. Clarendon Press, Oxford, p 289-317

Choat JH, Andrews NL (1986) Interactions among species in a guild of subtidal benthic herbivores. Oecologia 68: 387-394

Connell SD (2000) Floating pontoons create novel habitats for subtidal epibiota. J Exp Mar Biol Ecol 247:183-194

Connell SD, Glasby TM (1998) Do urban structures influence local abundances and diversity of subtidal epibiota? A case study from Sydney Harbour, Australia. Mar Environ Res 47:1-15

Creese RG (1982) Distribution and abundance of the acmeid limpet, Patelloida latistrigata, and its interaction with barnacles. Oecologia 52:85-96

Creese RG, Underwood AJ (1982) Analysis of inter- and intraspecific competition amongst intertidal limpets with different methods of feeding. Oecologia 53:337-346

Crowe TP (1999) Limits to generality: seasonal and temporal variation in dispersal of an intertidal gastropod. J Exp Mar Biol Ecol 232:177-196

Davis JLD, Levin LA, Walther SM (2002) Artificial armored shorelines: sites for open-coast species in a southern California Bay. Mar Biol 140:1249-1262

Dungan ML (1986) Three-way interactions: barnacles, limpets, and algae in a Sonoran desert rocky intertidal shore. Am Nat 127:292-316

Erlandsson J, Kostylev V, Williams GA (1999) A field technique for estimating the influence of surface complexity on movement tortuosity in the tropical limpet Cellana grata Gould. Ophelia 50:215-224

Fahrig L (2001) How much habitat is enough? Biol Conserv 100:65-74

Fairweather PG (1988) Movements of intertidal whelks (Morula marginalba and Thais orbita) in relation to availability of prey and shelter. Mar Biol 100:63-68

Faivre B, Préault $M$, Théry $M$, Secondi J, Patris B, Cézilly F (2001) Breeding strategy and morphological characters in an urban population of blackbirds, Turdus merula. Biol Conserv 102:271-283

Fletcher WJ, Creese RG (1985) Competitive interactions between co-occurring herbivorous gastropods. Mar Biol 86:183-191

Foster SA, Endler JA (1999) Geographic variation in behaviour: perspectives on evolutionary mechanisms. Oxford University Press, New York

Glasby TM (1999) Differences between subtidal epibiota on pier pilings and rocky reefs at marinas in Sydney, Australia. Estuar Coast Shelf Sci 48:281-290

Glasby TM (2000) Surface composition and orientation interact to affect subtidal epibiota. J Exp Mar Biol Ecol 248: $177-190$

Gray DR, Naylor E (1996) Foraging and homing behaviour of the limpet, Patella vulgata: a geographical comparison. J Molluscan Stud 62:121-124

Gray JS (1997) Marine biodivesity: patterns, threats and conservation needs. Biodivers Conserv 6:153-157

Hamilton PV (1977) Daily movements and visual location of plant stems by Littorina irrorata (Mollusca: Gastropoda). Mar Behav Physiol 4:293-304

Hawkins SJ, Hartnoll RG (1982) Settlement patterns of Semibalanus balanoides (L.) in the Isle of Man (1977-1981). J Exp Mar Biol Ecol 62:271-283

Hawkins SJ, Hartnoll RG (1983) The influence of barnacle cover on the number, growth and behaviour of Patella vulgata on a vertical pier. J Mar Biol Assoc UK 62:855-867

Hazlett BA (1988) Behavioural plasticity as an adaptation to a variable environment. In: Chelazzi G, Vannini M (eds) Behavioural adaptation to intertidal life. Plenum Press, New York, p 317-332

Holloway MG, Connell SD (2002) Why do floating structures create novel habitats for subtidal epibiota? Mar Ecol Prog Ser 235:43-52

Hughes RN (1980) Optimal foraging theory in the marine context. Oceanogr Mar Biol Annu Rev 18:423-481

Iwasaki K (1999) Short- and long-term movements of the patellid limpet Patella flexuosa within gaps in intertidal mussel beds. J Molluscan Stud 65:295-301

Levings SC, Garrity SD (1983) Diel and tidal movement of two co-occurring neritid snails: differences in grazing patterns on a tropical shore. J Exp Mar Biol Ecol 67:261-278

Little C (1989) Factors governing patterns of foraging activity in littoral marine herbivorous molluscs. J Molluscan Stud $55: 273-284$

Lubchenco J, Gaines SD (1981) A unified approach to marine plant-herbivore interactions. I. Populations and communities. Annu Rev Ecol Syst 12:405-437

Mackay DA, Underwood AJ (1977) Experimental studies on homing in the intertidal patellid limpet Cellana tramoserica (Sowerby). Oecologia 30:215-237

Mardia KV (1972) Statistics of directional data. Academic Press, London

Markus N (2002) Behaviour of the black flying fox Pteropus alecto. 2. Territoriality and courtship. Acta Chiropterol 4: 153-166

Menge BA (1995) Indirect effects in marine rocky intertidal 
interaction webs: patterns and importance. Ecol Monogr $65: 21-74$

Minchinton TE, Ross PM (1999) Oysters as habitat for limpets in temperate mangrove forests. Aust J Ecol 24:157-170

Moran MJ (1985) The timing and significance of sheltering and foraging behaviour of the predatory gastropod Morula marginalba Blainville (Muricidae). J Exp Mar Biol Ecol 93:103-114

O'Donnell MA (1984) Aspects of the ecology of the serpulid tubeworm, Galeolaria caespitosa (Polychaeta; Serpulidae). In: Hutchings PA (ed) Proc 1st Int Polychaete Conf. The Linnean Society of New South Wales, Milson's Point, p 355-360

Owings DH, Coss RG, McKernon D, Rowe MP, Arrowood PC (2001) Snake-directed antipredator behavior of rock squirrels (Spermophilus variegatus): population differences and snake-species discrimination. Behaviour 138:575-595

Reilly FJ, Spagnolo RJ, Ambrogio E (1996) Marine and estuarine shallow water science and management. Estuaries 19:165-168

Robertson CPJ, Baker PJ, Harris S (2000) Ranging behaviour of juvenile red foxes and its implications for management. Acta Theriol 45:525-535

Ruiz Sebastián C, Steffani CN, Branch GM (2002) Homing and movement patterns of a South African limpet Scutellastra argenvillei in an area invaded by an alien mussel Mytilus galloprovincialis. Mar Ecol Prog Ser 243:111-122

Santini G, Thompson RC, Tendi C, Hawkins SJ, Hartnoll RG, Chelazzi G (2004) Intra-specific variability in the temporal organization of foraging activity in the limpet Patella vulgata. Mar Biol 144:1165-1172

Sitati NW, Walpole MJ, Smith RJ, Leader-Williams N (2003) Predicting spatial aspects of human-elephant conflict. J Appl Ecol 40:667-677

Sousa WP (1985) Disturbance and patch dynamics on rocky intertidal shores. In: Pickett STA, White PS (eds) The ecology of natural disturbance and patch dynamics. Academic Press, London, p 101-124

Underwood AJ (1977) Movement of intertidal gastropods. J Exp Mar Biol Ecol 26:191-201

Underwood AJ (1980) The effects of grazing by gastropods and physical factors on the upper limits of distribution of intertidal macroalgae. Oecologia 46:201-213

Editorial responsibility: Roger Hughes (Contributing Editor), Bangor, UK
Underwood AJ (1984) Vertical and seasonal patterns in competition for microalgae between intertidal gastropods. Oecologia 64:211-222

Underwood AJ (1988) Design and analysis of field experiments on competitive interactions affecting behaviour of intertidal animals. In: Chelazzi G, Vannini M (eds) Behavioural adaptations to intertidal life. Plenum Press, New York, p 333-358

Underwood AJ (1997) Experiments in ecology: their logical design and interpretation using analysis of variance. Cambridge University Press, Cambridge

Underwood AJ, Chapman MG (1985) Multifactorial analyses of directions of movement of animals. J Exp Mar Biol Ecol 91:17-43

Underwood AJ, Chapman MG (1989) Experimental analysis of the influences of topography of the substratum on movements and density of an intertidal snail, Littorina unifasciata. J Exp Mar Biol Ecol 134:175-196

Underwood AJ, Jernakoff P (1981) Effects of interactions between algae and grazing gastropods on the structure of a low-shore intertidal algal community. Oecologia 48: 221-233

Underwood AJ, Denley EJ, Moran MJ (1983) Experimental analysis of the structure and dynamics of mid-shore rocky intertidal communities in New South Wales. Oecologia 56: 202-219

Vadas RL, Elner RW, Garwood PE, Babb IG (1986) Experimental evaluation of aggregation behaviour in the sea urchin Strongylocentrotus droebachiensis: a reinterpretation. Mar Biol 90:433-448

Warne RM, Jones DN (2003) Evidence of target specificity in attacks by Australian magpies on humans. Wildl Res 30: 265-267

Wells RA (1980) Activity pattern as a mechanism of predator avoidance in two species of acmaeid limpet. J Exp Mar Biol Ecol 48:151-168

Williams GA, Little C, Morritt D, Stirling P, Teagle L, Miles A, Pilling G, Consalvey M (1999) Foraging in the limpet Patella vulgata: the influence of rock slope on the timing of activity. J Mar Biol Assoc UK 79:881-889

Yapp GA (1986) Aspect of population, recreation and management of the Australian coastal zone. Coast Zone Manage J 14:47-66

Submitted: March 25, 2004; Accepted: July 26, 2004 Proofs received from author(s): October 7, 2004 